BMC

\title{
Cancer
}

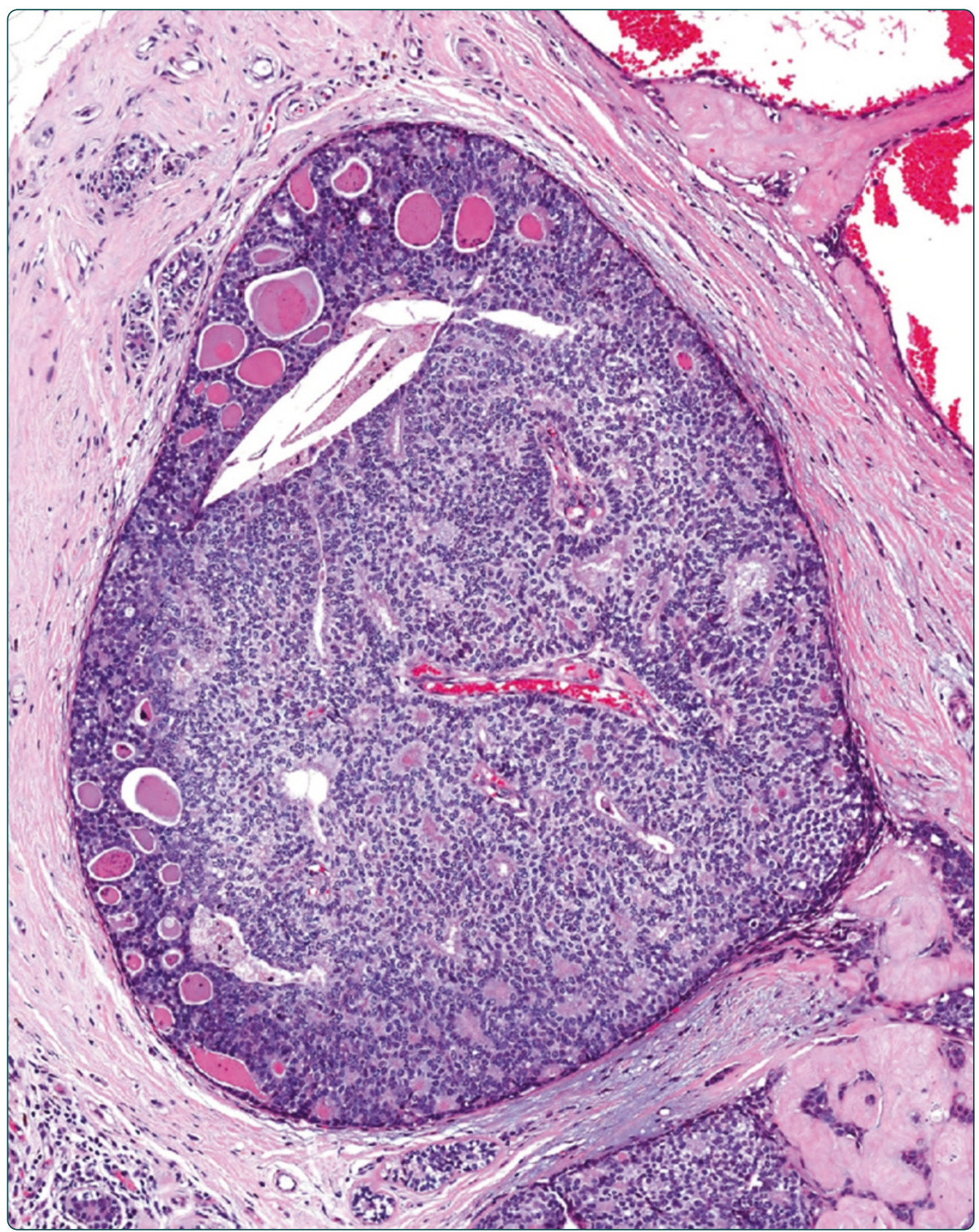

\section{Vascular measurements correlate with estrogen receptor status}

Lloyd et al. 


\title{
Vascular measurements correlate with estrogen receptor status
}

\author{
Mark C Lloyd ${ }^{1,3^{*}+}$, Khalid O Alfarouk ${ }^{1,2^{*}+}$, Daniel Verduzco ${ }^{1}$, Marilyn M Bui ${ }^{1}$, Robert J Gillies ${ }^{1}$, Muntaser E Ibrahim², \\ Joel S Brown ${ }^{3}$ and Robert A Gatenby ${ }^{1}$
}

\begin{abstract}
Background: Breast carcinoma can be classified as either Estrogen Receptor (ER) positive or negative by immunohistochemical phenotyping, although ER expression may vary from 1 to $100 \%$ of malignant cells within an $E R+$ tumor. This is similar to genetic variability observed in other tumor types and is generally viewed as a consequence of intratumoral evolution driven by random genetic mutations. Here we view cellular evolution within tumors as a classical Darwinian system in which variations in molecular properties represent predictable adaptations to spatially heterogeneous environmental selection forces. We hypothesize that ER expression is a successful adaptive strategy only if estrogen is present in the microenvironment. Since the dominant source of estrogen is blood flow, we hypothesized that, in general, intratumoral regions with higher blood flow would contain larger numbers of ER + cells when compared to areas of low blood flow and in turn necrosis.
\end{abstract}

Methods: This study used digital pathology whole slide image acquisition and advanced image analysis algorithms. We examined the spatial distribution of ER + and ER- cells, vascular density, vessel area, and tissue necrosis within histological sections of 24 breast cancer specimens. These data were correlated with the patients ER status and molecular pathology report findings.

Results: ANOVA analyses revealed a strong correlation between vascular area and ER expression and between high fractional necrosis and absent ER expression $\left(R^{2}=39 \% ; p<0.003\right.$ and $\left.R^{2}=46 \% ; p<0.001\right)$, respectively). ER expression did not correlate with tumor grade or size.

Conclusion: We conclude that ER expression can be understood as a Darwinian process and linked to variations in estrogen delivery by temporal and spatial heterogeneity in blood flow. This correlation suggests strategies to promote intratumoral blood flow or a cyclic introduction of estrogen in the treatment schedule could be explored as a counter-intuitive approach to increase the efficacy of anti-estrogen drugs.

Keywords: Darwinian dynamics, ER, Breast cancer, Selection, Phenotypic prediction, Vasculature, Hecrosis

\section{Background}

Estrogen (17 $\beta$-estradiol) is a circulating steroid hormone that binds to intracellular estrogen receptors (ER) after passively diffusing through the plasma membrane (Thomas et al. [1]). Estrogen frequently plays a crucial role in breast tumorigenesis by promoting cellular proliferation, and

\footnotetext{
*Correspondence: Mark.Lloyd@moffitt.org; Alfarouk@Hala-Alfarouk.org ${ }^{\dagger}$ Equal contributors

'H. Lee Moffitt Cancer Center, 12902 Magnolia Drive, Tampa, FL 33612, USA ${ }^{2}$ Unit of Diseases and Diversity, Dept. of Molecular Biology, Institute of Endemic Diseases, University of Khartoum, Medical Campus, P. O. BOX 102, Khartoum, Sudan

Full list of author information is available at the end of the article
}

decreasing apoptosis ([2-4]; Russo et al. [5]; Yager et al. [6]). ER expression in breast cancers is used as a prognostic and predictive tool that reliably correlates with the clinical progression of disease and its response to hormonal therapies.

Although the ER status of breast carcinomas is typically expressed as simply positive or negative, there is frequently considerable heterogeneity of ER expression among cells of the same tumor. In fact, typical classification of a tumor as ER positive requires only $1 \%$ of the cells expresses ER (Hammond et al. [7]). There is now evidence $[8,9]$ that the prevalence of ER expression within cells in the same tumor correlates with the degree and duration of response to anti-estrogen therapy.

\section{Biomed Central}


Our goal here is to investigate the evolutionary and ecological forces that govern heterogeneity of ER expression in breast cancers. Recent studies have demonstrated substantial heterogeneity in cells within the same tumor as a result of intratumoral evolution [10-14]. Generally, this heterogeneity is viewed as a genetic process in which stochastic mutations generate new populations in an unpredictable if not chaotic process. We note, however, that genetic changes are simply one component of evolution and that intratumoral Darwinian dynamics emerge fundamentally from environmental selection forces that promote phenotypic (not genotypic) adaptations [15]. Furthermore, we acknowledge that a large body of work exists which addresses the complex dynamics of ER expression in vitro $[16,17]$ and in vivo (Shipitson et al. [18]). We embrace these works and do not suggest that phenotypic adaptation alone is sufficient explain variation in ER expression.

Instead, we propose that intratumoral cellular heterogeneity represents a predictable process driven by variations in environmental selection forces leading to predictable and reproducible adaptive strategies. The most obvious source of environmental selection is blood flow which, in most cancers, is spatially and temporally heterogeneous resulting in regions of necrosis in poorly perfused regions.

We propose that ER expression will be observed if it provides an adaptive advantage. Specifically, we propose that ER will be expressed only when estrogen is present in the microenvironment. When estrogen is absent, ER expression represents a needless expenditure of resources and will be selected against. Since the source of estrogen in the breast is typically (although not always) interstitial fluid and moves from the vessels into the cell by a simple reaction diffusion model identical to oxygen, nutrients, etc. [19], we propose the hypothesis that ER + cells will be found in regions of high blood flow while ER- cells will be present in regions of poor blood flow. This results in the prediction that the prevalence of ER + cells will generally follow the distribution of blood flow. To test this hypothesis we examined regional distribution of ER + and ER- cells compared to vascular density and regional necrosis within 24 clinical breast cancers of variable ER status and tumor grade.

\section{Methods}

\section{Sample selection and collection}

Twenty-four (24) clinically identified breast cancer cases were selected via pathology report reviews by a board certified pathologist (MMB) with the approval of the University of South Florida Institutional Review Board and the Moffitt Cancer Center Scientific Review Committee. Data for each case include the pathologist's estimation of percent ER + cells, ER stain intensity, and the semi-quantitative Allred score [20] and histological score. The cases cover a wide spectrum of diagnostic stages including ductal carcinoma in situ (DCIS) $(\mathrm{n}=11)$, invasive ductal carcinoma Nottingham Grade I $(n=4)$, Grade II $(\mathrm{n}=4)$ and Grade III $(\mathrm{n}=5)$. Similarly, the ER status, based on the pathology report, ranged from 0 - $100 \%$ positive and the Allred and histological score were used to create four classification ranges. The Allred score is the sum of a proportion score reflecting the percentage of positive-staining tumor cells ( 0 , none; $1,1 / 100 ; 2,1 / 100$ to $1 / 10 ; 3,1 / 10$ to $1 / 3$; $4,1 / 3$ to $2 \beta$; and $5,>2 \beta$ ) and an intensity score representing the average intensity of positive tumor cells $(0$, none; 1 , weak, 2, intermediate; and 3, strong). The proportion and intensity scores are added to obtain a total score, which ranges from 0 to 8 . (Harvey [21]). The $\mathrm{H}$ score is a combination of staining intensity and extent according to the following formula: $\mathrm{H}$ score $=1 \times \%$ of tumor cells with weak staining $+2 \times \%$ of tumor cells with moderate staining +3 $\times \%$ of tumor cells with strong staining, resulting in a total score of $0-300$ (Elston [22]). Although the ER intensity, Allred and H-Scores were variable for the ER + cases used to measure the vascular density and necrotic area, the percentage of ER positive cells in the positive cases was always greater than $90 \%$. This fact made it challenging to assess the spatial distribution of ER positivity in these cases. An additional five cases were selected with $<60 \%$ ER positivity and used to specifically evaluate the spatial distribution of ER positivity with respect to vasculature.

The hematoxylin and eosin $(\mathrm{H} \& \mathrm{E})$ stained sections used for diagnosis from each identified case were retrieved from the department archives and confirmed by the study pathologist (MMB). The blocks identified to have sufficient material and most representative of each case was retrieved from the Cancer Center archives for the purposes of these studies.

\section{Histology}

For each of the 24 blocks selected for this study, serial unstained sections were cut at a thickness of $4 \mu \mathrm{m}$ using standard microtomy practices and placed on charged glass slides. The order in which the sections were cut was recorded. The first section was stained with $H \& E$, using standard histological technique. The subsequent serial sections were stained using a mouse monoclonal antibody that reacts to CD34, (\#CMA334, Cell Marque, Rocklin, CA) at the stock prediluted concentration and mouse monoclonal ER- $\beta$ (\#ab5786, Abcam, Cambridge, MA) at 1:250 dilution and monoclonal antibody VEGF VG1 (\#M7273, Dako, Carpinteria, CA) at 1:500 dilution. These slides were incubated for 16 minutes at room temperature The Ventana OmniMap anti-mouse secondary antibody was incubated for $12 \mathrm{~min}$. The Ventana ChromoMap kit detection system was used according to the kit protocol and slides were then counterstained with hematoxylin. Appropriate positive and negative controls were used. Slides were covered with \#1.5 thick cover glass. 


\section{Image acquisition}

Whole slide images (WSI) were produced using an Aperio (Vista, CA, USA) ScanScope XT digital slide scanner with a $20 \times / 0.75 N A$ lens. Using the Basler tri-linear array detection, stitching was minimized and the time to scan for most WSIs did not exceed five minutes. Digital WSIs were retained on servers housed within the Moffitt Network Operations Center and accessible on any networked computer via the password protected Spectrum (Aperio) database.

\section{Image analysis \\ H\&E segmentation}

The commercially available Genie histology pattern recognition platform (Aperio) was trained to classify regions of interest within each of the 13 invasive $H \& E$ stained samples. DCIS was analyzed separately to account for the central comedo necrosis common to this non-invasive stage. By manually selecting regions of necrosis, viable tumor and other tissues (including, but not limited to: skin, adipose tissue, and normal margins) the software was trained with the following settings (1000 iterations of uniform distribution with 0.01 as a regularization parameter over 20 stage iterations with eight and three iterations per first and second stage, respectively). Application of this training set over the entire WSI for each patient allowed for computationally derived region segmentation. Each case was carefully quality controlled by a board certified pathologist (MMB).

\section{Vasculature identification and quantification}

The CD34 stained slides were segmented by the region classification methods described above. Furthermore, the CD34 positive vessels were identified using the Aperio vasculature algorithm with the following settings (Lumen and closed vessels including incomplete vessels with filtering $=2$; low $=160$; high $=210$; with stain components .27, .57 and .78 [RGB]). This algorithm was used to export the quantified values for vessel perimeter, area and lumen area.

\section{ER identification and quantification}

The ER stained slides were segmented by region classification methods using Definiens Tissue Studio (Munich, Germany). The DCIS and invasive tumor components were identified as the regions of interest and each cell was segmented and classified into negative (masked blue), low (yellow), moderate (orange) and high (red) intensity using the following parameters (IHC Thres $=0.5$; Thres low $/$ moderate $=0.75$; Thres moderate $/$ high $=1.0$ )

Resultant classification images from the cell identification, segmentation and classification methods were overlain with vessel mask images from CD34 staining using Image Pro Plus v.6.0.1 (Media Cybernetics, Bethesda,
MD). These images were used to measure the shortest distance between each cell and the nearest identified vessel.

\section{Statistical analysis}

A partially-hierarchical ANOVA (SYSTAT version 13) analysis was used to test for the effects vessel number, four parameters of vessel size (mean vessel area, mean vessel perimeter, maximum vessel size and mean lumen area) and the percentage of tissue which is necrotic on the tumor grade and ER status of each case. The dependent variables were the different feature data (i.e. vessel number, mean lumen area and percentage of necrotic area) and the independent variables were ER status and tumor grade. The 24 cases being analyzed were the samples.

\section{Results}

Vasculature availability

CD34 positive blood vessels within a manually edited buffer of $300 \mu \mathrm{m}$ from any tumor cell in all directions were identified and individually quantified for each sample. The metrics collected included the number of vessels in the sample. No correlation between vessel number and ER status was elucidated $\left(\mathrm{R}^{2}=7 \% ; \mathrm{p}=0.689\right)$.

The vessel size (mean vessel area, mean vessel perimeter, maximum vessel area and mean lumen area)) of the blood vessels was much lower in the samples which did not express ER compared to the ER + samples as evidenced in Figure 1 and Table 1. In aggregate the ER- samples exhibited a mean vessel area of $176 \mu \mathrm{m}^{2}$ compared to $359 \mu \mathrm{m}^{2}$ in $E R+$ patients $\left(R^{2}=37 \% ; \mathrm{p}=0.003\right)$. The perimeter increased from $87 \mu \mathrm{m}$ in ER- to $151 \mu \mathrm{m}$ in ER + $\left(R^{2}=40 \% ; p=0.003\right)$. Even the maximum vessel area and lumens of the vessels increased from $25 \mu^{2}$ in ER- to $41 \mu \mathrm{m}^{2}$ in the ER + cohort $\left(\mathrm{R}^{2}=18 \% ; \mathrm{p}=0.059\right)$. To reiterate, the mean vessel diameter of the vasculature of the $E R+$ regions was about twice that of the vessels if ER-samples in each of the three measures. Vessels identified in the ER- regions never exceeded a mean area over $300 \mu \mathrm{m}^{2}$ while 14 of the $18 \mathrm{ER}+$ cases exhibited a mean exceeding $300 \mu \mathrm{m}^{2}$ with a maximum of $671.4 \mu \mathrm{m}^{2}$ (Table 2) $\left(\mathrm{R}^{2}=16 \% ; \mathrm{p}=0.08\right)$. Vessel size was not found to be correlated with disease progression $(p=0.295)$. In other words, vessel size was not statistically different in DCIS samples compared to those of grade I, II or III invasive cancers yet the same metrics of vessel size was highly correlated with ER status (Figure 2). Furthermore, the vascular density (vessels/area) was not correlated with ER status or disease progression ( $p=0.476)$.

Increasing mean vessel area is associated with increasing tumor perfusion which might represent potential good prognostic value [23], and increasing survival rate [24], because tumor oxygenation increases survival rate through improving radiation, chemotherapy and reduces metastatic potentiality (Overgaard et al. [25-27]; 


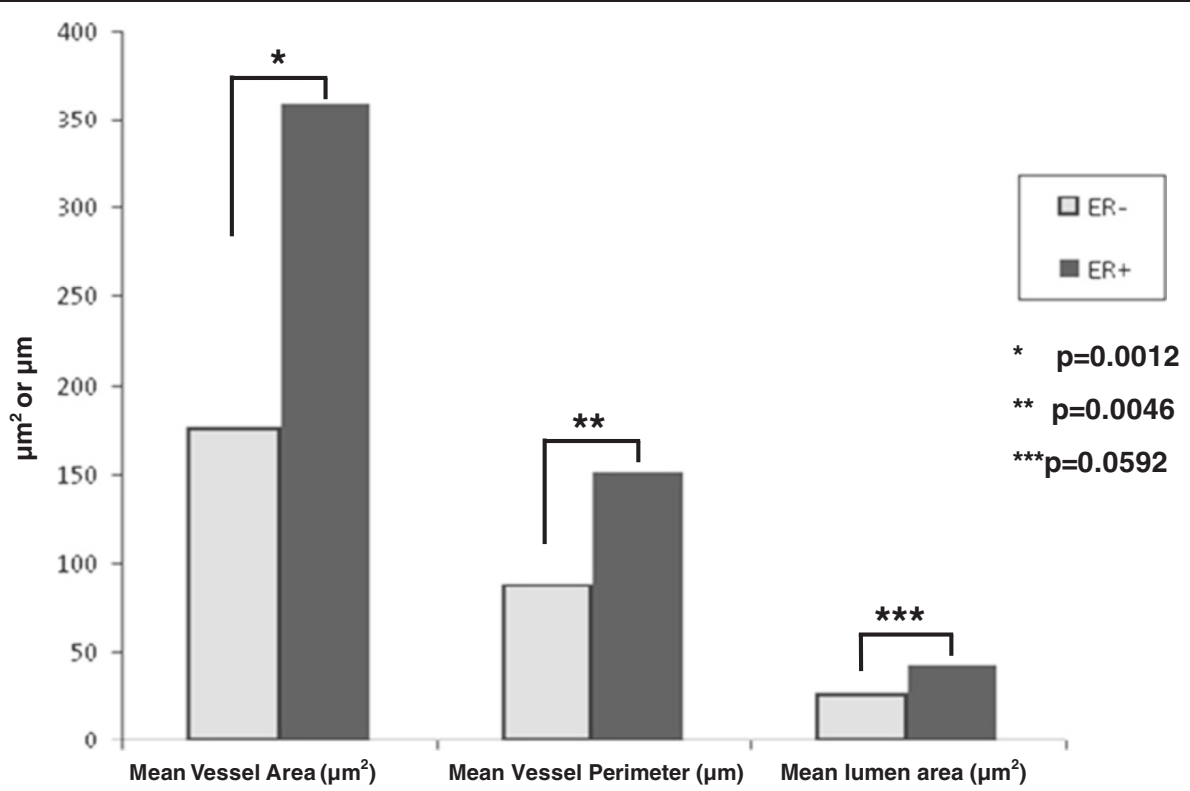

Figure 1 Vascular quantification. This graph demonstrates the quantified vascular differences between ER + and ER- samples. Largely, the ER + samples exhibit vessel area, perimeter length and lumen size which are statistically significant to demonstrate increased size as compared to the vessels in ER- samples.

Jain et al. [28]). These data confirmed that ER-positive tumors have relatively higher average vessel size that might indicate good prognostic value in compare to ER-negative tumors (Teschendorff et al. [29]; [30]).

The spatial distribution of ER positivity with respect to vasculature has been of great interest. Five IDC cases were stained with ER ( $<60 \%$ positivity) were used to specifically evaluate the spatial distribution of ER positivity with respect to identifiable blood vessels. Here the study pathologist (MMB) identified visible vasculature directly from the ER stained slides and from CD34 stained serial sections. Larger vessels were clearly identifiable and demonstrated proximal $(<30 \mu \mathrm{m})$ ER positivity in $76.5 \%$ (26 of 34 ) visible vessels. Furthermore, for all lesions proximal to vasculature the overall ER positivity was $43.3 \%$ and the moderate to strong positivity was $31.5 \%$ whereas, conversely, in the lesions distant to vessels ER positivity dropped to $26.3 \%$ and the moderate to strong positivity was observed to be $9.3 \%$.

\section{Necrosis}

Necrosis was once often associated with poor vascularization, subsequent hypoxia and the resultant cell death

Table 1 Vascular quantification

\begin{tabular}{lcc}
\hline & ER- & Er+ \\
\hline Mean vessel area (um2) & 175.6 & 358.5 \\
Mean vessel perimeter (um) & 87.1 & 151.2 \\
Mean lumen area (um2) & 24.6 & 40.7 \\
\hline
\end{tabular}

Quantified values of mean vascularity for ER + and ER- patients.
[31,32]. Other studies have shown that in fact high vascularization is correlated with necrotic zone expansion [33]. In this study necrosis was segmented from the viable tumor and other tissues including normal margins, adipose tissues et cetera. First, it was necessary to segment the patients by diagnosis so central comedo necrosis commonly found in DCIS patients did not over inflate the results of the invasive population. Regardless of the diagnosis, the viable tumor to necrotic area ratio was calculated for each sample (Table 2). Summary statistics were calculated by ER negative and ER positive groups for each diagnostic category. The mean necrosis area in invasive ER-samples was observed to be $24.3 \%$. By contrast, necrosis was quantified to be $4.2 \%$ in ER + tumor samples, demonstrating significantly lower necrosis in ER + tumors as compared to ER- tumors $\left(R^{2}=46 \% ; p<0.001\right)$. Of the $E R+$ invasive samples 8 of 11 had less than 5\% necrosis (Figure 3).

Similarly, the DCIS ER- group exhibited $21.3 \%$ necrosis area per total tumor area while ER + DCIS cases were quantified to contain $4.4 \%$ necrosis. Of the DCIS ER + samples 6 of 8 had less than $5 \%$ necrosis. These data demonstrate in this sample group that ER-negative tumors have higher necrotic core area relative to viable tumor area. Furthermore, the amount of necrosis in DCIS samples was not found to be dependent on the size of the DCIS or the availability of vasculature outside of the basement membrane of the duct itself. Initially, we hypothesized in DCIS increased necrosis would correlate with ductal size and in turn the distance from the center of the 
Table 2 Quantification metrics for all patients

\begin{tabular}{|c|c|c|c|c|c|c|c|c|c|c|c|}
\hline $\begin{array}{l}\text { De-ID } \\
\text { patient \# }\end{array}$ & $\begin{array}{l}\text { Er }+ \\
\text { or } \\
\text { ER- }\end{array}$ & $\begin{array}{l}\text { Percent } \\
\text { ER+ } \\
\text { cells }\end{array}$ & $\begin{array}{c}\text { Stain } \\
\text { intensity }\end{array}$ & $\begin{array}{l}\text { Allred } \\
\text { score }\end{array}$ & $\begin{array}{l}\text { Histological } \\
\text { score }\end{array}$ & $\begin{array}{l}\text { \# of vessels } \\
\text { per unit } \\
\text { area (um2) }\end{array}$ & $\begin{array}{l}\text { Maximum } \\
\text { vessels } \\
\text { area (um2) }\end{array}$ & $\begin{array}{l}\text { Mean } \\
\text { vessels } \\
\text { area (um2) }\end{array}$ & $\begin{array}{l}\text { Mean vessels } \\
\text { perimeter } \\
\text { (um) }\end{array}$ & $\begin{array}{l}\text { Mean } \\
\text { lumen } \\
\text { area (um2) }\end{array}$ & $\begin{array}{l}\text { Necrotic } \\
\text { area per } \\
\text { tumor area } \\
\end{array}$ \\
\hline Patient 1 & - & 0 & 0 & 0 & 0 & $2.12 \mathrm{E}-04$ & 1301 & 197.3 & 91.5 & 47.5 & 23.1 \\
\hline Patient 2 & - & 0 & 0 & 0 & 0 & 7.97E-05 & 153 & 63.1 & 41.4 & 7.7 & 69.3 \\
\hline Patient 3 & - & 0 & 0 & 0 & 0 & $3.67-04$ & 2124 & 224.4 & 107.4 & 21.2 & $<.5$ \\
\hline Patient 4 & - & 0 & 0 & 0 & 0 & 5.19E-05 & 329 & 102.8 & 58.2 & 8.2 & 16.2 \\
\hline Patient 5 & - & 0 & 0 & 0 & 0 & $1.14 \mathrm{E}-03$ & 12195 & 287.9 & 141.5 & 34.4 & 22.4 \\
\hline Patient 6 & - & 0 & 0 & 0 & 0 & $1.56 \mathrm{E}-03$ & 8609 & 178.0 & 82.9 & 28.9 & 14.9 \\
\hline Patient 7 & + & 90 & $1+$ to $3+$ & 6 & 150 & 6.19E-04 & 13082 & 482.8 & 195.7 & 72.3 & 33.7 \\
\hline Patient 8 & + & 95 & $1+$ to $3+$ & 7 & 155 & 4.35E-04 & 4560 & 307.4 & 142.1 & 44.6 & 1.1 \\
\hline Patient 9 & + & 95 & $1+$ to $3+$ & 7 & 165 & 8.38E-04 & 12672 & 282.1 & 122.8 & 40.4 & $<.5$ \\
\hline Patient 10 & + & 90 & $2+$ & $7+$ & 170 & 7.23E-04 & 14879 & 347.7 & 153.3 & 34.8 & 22.1 \\
\hline Patient 11 & + & 100 & $1+$ to $3+$ & 8 & 200 & 4.79E-05 & 1784 & 368.6 & 138.2 & 33.3 & 4.7 \\
\hline Patient 12 & + & 95 & $1+$ to $3+$ & 7 & 240 & 5.39E-04 & 6274 & 267.6 & 107.4 & 61.5 & $<.5$ \\
\hline Patient 13 & + & 100 & $2+0$ to $3+$ & 8 & 260 & 5.59E-05 & 7927 & 671.4 & 258.4 & 16.5 & 5.2 \\
\hline Patient 14 & + & 90 & $3+$ & 8 & 270 & $9.18 \mathrm{E}-04$ & 19704 & 465.8 & 191.7 & 23.2 & 2.5 \\
\hline Patient 15 & + & 90 & $3+$ & 8 & 270 & 7.66E-04 & 16094 & 341.9 & 130.9 & 21.7 & $<.5$ \\
\hline Patient 16 & + & 100 & $2+$ to $3+$ & 8 & 270 & 4.67E-04 & 1712 & 178.8 & 98.7 & 40.4 & 1.6 \\
\hline Patient 17 & + & 100 & $2+$ to $3+$ & 8 & 270 & 7.27E-04 & 19485 & 436.3 & 174.1 & 29.3 & $<.5$ \\
\hline Patient 18 & + & 100 & $2+$ to $3+$ & 8 & 280 & 8.26E-04 & 4379 & 221.2 & 110.9 & 65.8 & $<.5$ \\
\hline Patient 19 & + & 100 & $3+$ & 8 & 300 & $2.35 \mathrm{E}-04$ & 1619 & 172.4 & 80.6 & 30.9 & 3.9 \\
\hline Patient 20 & + & 100 & $3+$ & 8 & 300 & $8.78 \mathrm{E}-05$ & 3673 & 312.2 & 152.3 & 17.6 & $<.5$ \\
\hline Patient 21 & + & 100 & $3+$ & 8 & 300 & 5.03E-04 & 8258 & 271.8 & 115.4 & 47.7 & $<.5$ \\
\hline Patient 22 & + & 100 & $3+$ & 8 & 300 & 4.87E-04 & 17390 & 373.7 & 158.7 & 52.3 & $<.5$ \\
\hline Patient 23 & + & 100 & $3+$ & 8 & 300 & 7.74E-04 & 14857 & 512.3 & 237.2 & 58.8 & $<.5$ \\
\hline Patient 24 & + & 100 & $3+$ & 8 & 300 & 7.03E-04 & 11188 & 438.0 & 156.7 & 40.9 & $<.5$ \\
\hline Neg control & NA & NA & NA & NA & NA & 1.72E-04 & 2207 & 116.1 & 59.3 & 6.3 & NA \\
\hline Pos control & NA & NA & NA & NA & NA & $9.78 \mathrm{E}-04$ & 11836 & 345.8 & 156.3 & 22.4 & NA \\
\hline
\end{tabular}

Summary of all quantification metrics for all patients.

gland to vascular resources. This was not the case in our results. The average diameter of ER- DCIS with central necrosis was $668 \mu \mathrm{m}$. The average diameter of ER + DCIS without central necrosis was $702 \mu \mathrm{m}$. Examples of the levels of necrosis in ER = and ER- samples are available in Figure 4. Also of interest, in a single case vasculature was observed inside the DCIS. This case was not found to contain necrosis and was ER + (Figure 4E). Finally, adjacent normal breast tissues were also investigated to understand whether or not the vasculature of adjacent normal tissues correlated with the ER positivity in the nearest lesions. The vascularization studies were performed on ten samples which we either $0 \% \mathrm{ER}+(\mathrm{n}=5)$ or $>90 \% \mathrm{ER}+(\mathrm{n}=5)$. However, there were no observable differences between the vessel features in the adjacent normal tissues.

\section{Discussion}

ER expression is a useful predictive and prognostic biomarker in breast cancer, however, is often extremely variable even within the same tumor. Similar to cellular heterogeneity found in other cancers [10-14], this variation in ER staining is a consequence of intratumoral evolutionary dynamics (Figure 5). Here we address the Darwinian dynamics that might govern cellular ER expression. There are two general components of ER evolution. The first, which cannot be answered with our current study, is the variability of ER expression in the same tumor. Can breast cancer cells adjust ER expression (and other growth factor receptors) so that ER + and - cells in the same tumor represent a single generalist population that phenotypically adapts to various environments? Alternatively the ER expression could be 


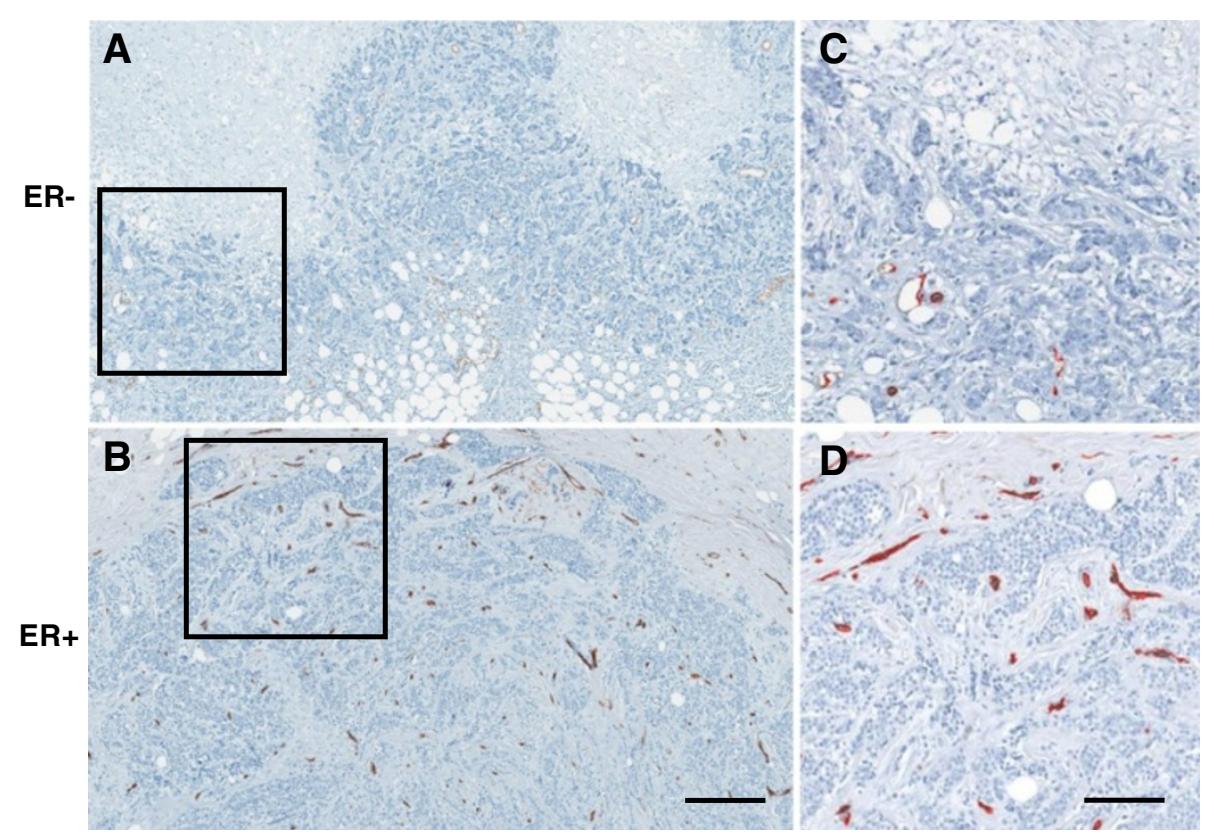

Figure 2 Representative vasculature images. A) ER- Grade III invasive breast cancer tumor stains against CD34 with as few as 13 quantified vessels at a region adjacent to the tumor edge. Scale $=800 \mu \mathrm{m}$. This may be compared with $\mathbf{B}) E R+C D 34$ stained grade III tumor which has as many as 84 vessels in the same area as evidenced by $\mathbf{C}$ ) and $\mathbf{D}$ ) which are enlarged views of the inset areas with quantified vessels of each masked in red. Scale bar $=200 \mu \mathrm{m}$.

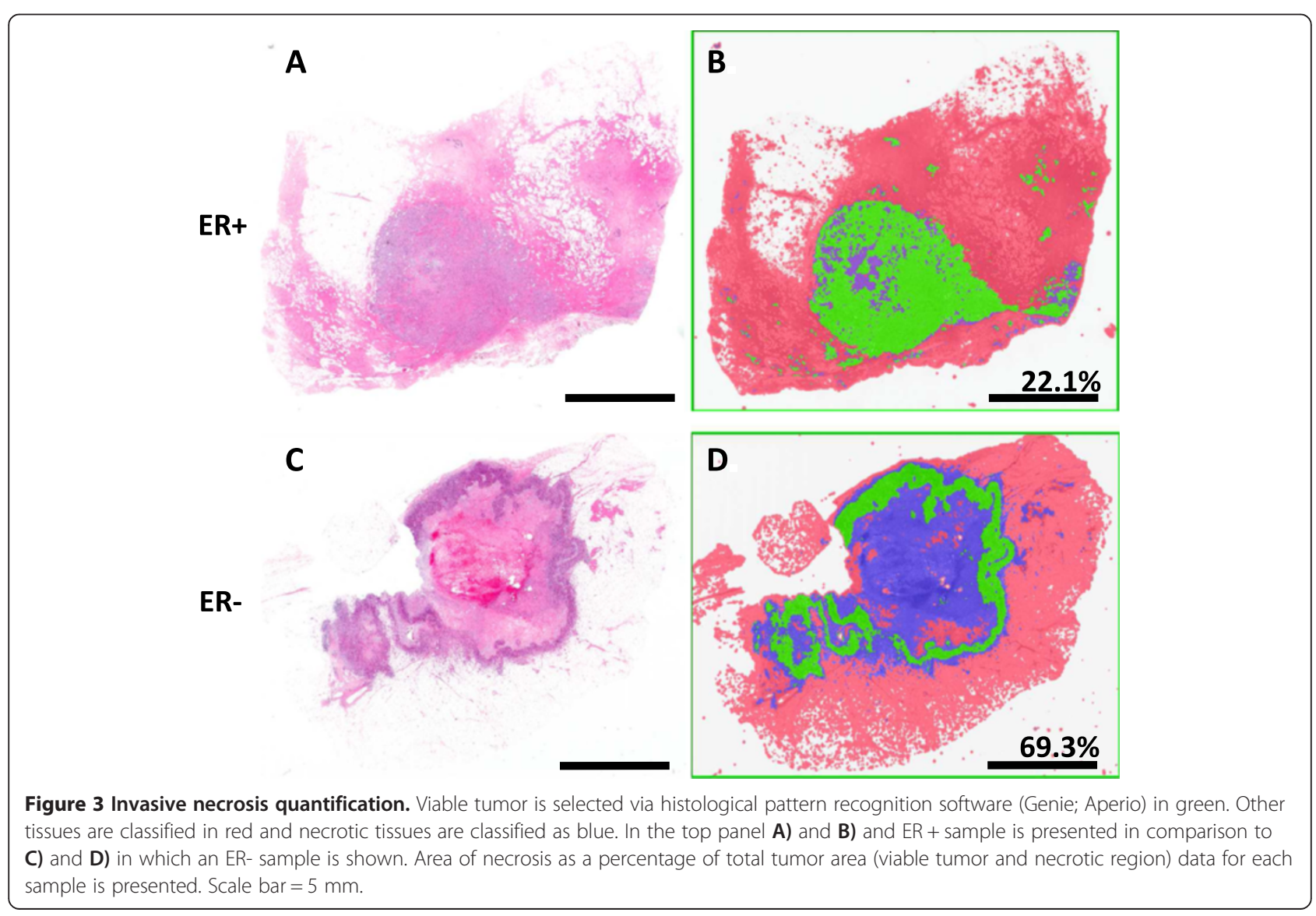




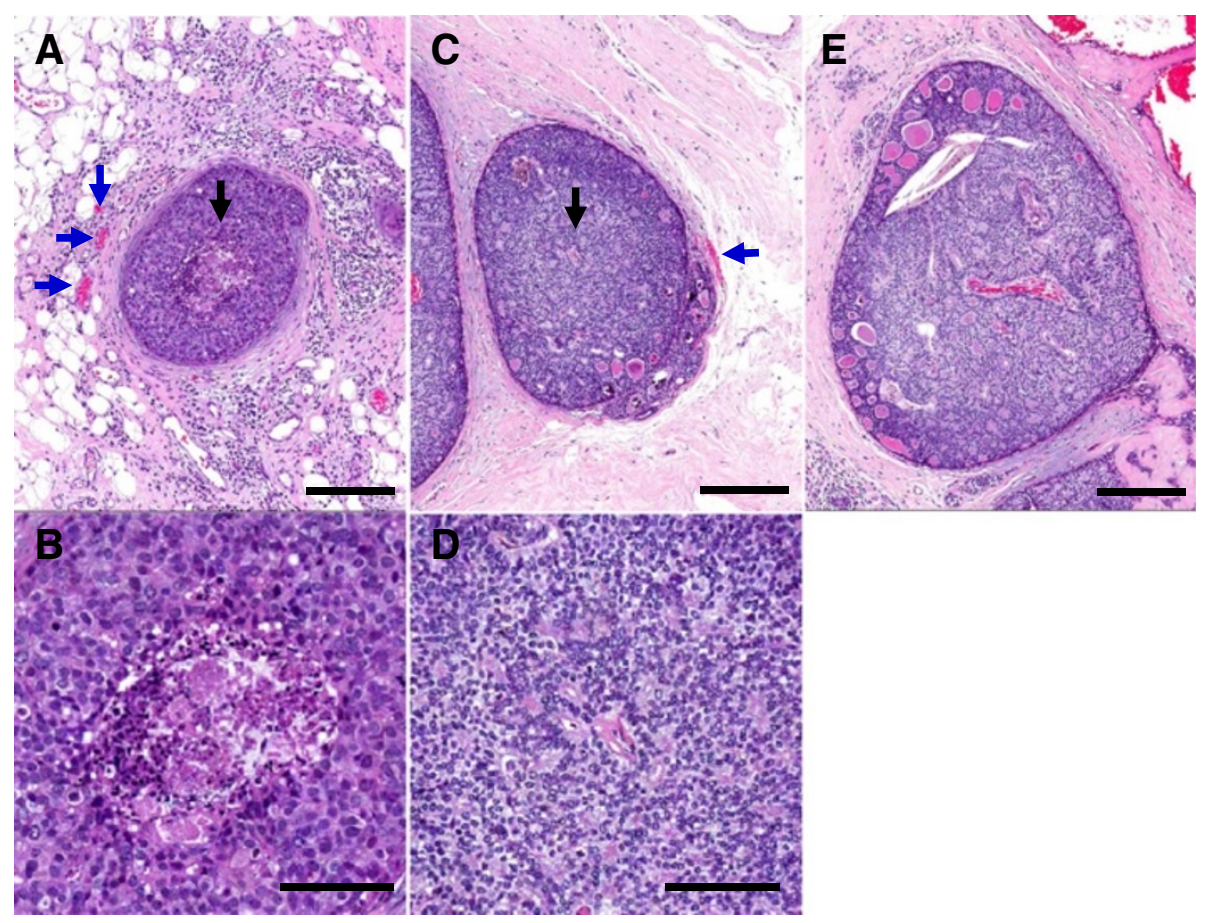

Figure 4 Ductal carcinoma in situ localization. This is a DCIS lesion from A) an ER- patient with central necrosis. Note the regionally adjacent vessels outside the lesion (blue arrows) and $\mathbf{B}$ ) the enlarged image of the central necrosis localized under the black arrow. C) DCIS from an $\mathrm{ER}+$ patient without central necrosis despite the size and distance from the center to vasculature; $\mathbf{D})$ as illustrated by the lack of necrosis in the enlarged region uder the black arrow. E) Shows a large $(>1 \mathrm{~mm})$ DCIS sample with interior vasculature. This sample does not exhibit necrosis and this patient is ER+. Top row scale bars $=250 \mu \mathrm{m}$; bottom row scale bars $=100 \mu \mathrm{m}$.

a relatively fixed property and then ER + and - cells represent separate, specialist populations. The second component of intratumoral Darwinian dynamics is the environmental factors that are selection forces that define phenotypic fitness. This is the focus of our current work.

Here we propose that spatial heterogeneity in ER expression is the sequela of intratumoral evolution driven not by random mutations but by variations in environmental selection forces and predictable cellular adaptive strategies. We specifically hypothesize that ER expression will correlate with local concentrations of estrogen. Since estrogen diffusion from blood vessels is spatially limited by reaction-diffusion kinetics similar to oxygen and glucose, we predict a correlation between vascularization, necrosis and ER expression (Teschendorff et al. [29]; [30-32]). In order to test cell density as a plausible barrier of diffusion we evaluated the mean cell number per $\mathrm{mm}^{2}$ and

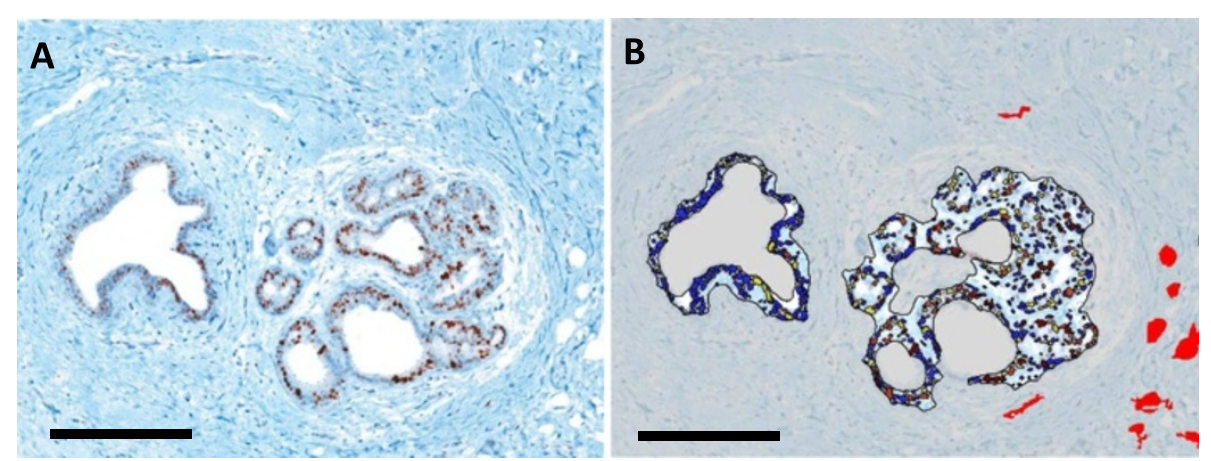

Figure 5 ER positivity in DCIS relative to vascular localization: A) DCIS lesions stained this ER were B) isolated from the adjacent stroma and the individual cells were segmented and classified as negative (blue), weak (yellow), moderate (orange) and strong (red) stain intensity expression. Simultaneously CD34 serial sections were used to identify, isolate and mask (red) vessels. Together this image demonstrates an overlain image set of ER classification and vessel localization. Cells nearer the vasculature were observed to have stronger ER expression than cells distant from the vessels. Scale bars $=250 \mu \mathrm{m}$. 
did not find any significant difference in the 24 samples evaluated. This suggests cell density alone does not correlate with ER status.

Our results do show that ER + tumors are associated with larger blood vessels and a lower percentage of tissue necrosis. It should however be noted that differences in CD34 staining may over or underestimate the vascularity due to tumor-specific alterations in the vascular bed such that not all of the endothethial cells may be appreciated. Our initial prediction that vessel number will increase in ER + samples was not supported. However, the interaction between vessel size and ER status was three times higher than the interactions between tumor grade and ER status and vessel area. Our second hypothesis, that ER status would be inversely correlated with necrosis, was even more strongly supported. This suggests that as ductal carcinoma in situ progresses towards invasion, 1) the larger the vasculature is early in disease progression, the lower the volume of necrosis and 2) if necrosis does not increase with the cancer progression, then ER + cells are more likely to dominate the population.

While the number of patients evaluated in this study is limited, and a larger patient population would be desirable, the number of individual vessels evaluated is on the order of $10^{3}$ to $10^{4}$ per patient. For this reason, our results indicate statistical significance to detect differences between ER positive and negative patients.

Furthermore, the amount of necrosis in DCIS samples was not found to be dependent on the size of the DCIS or the availability of vasculature outside of the basement membrane of the duct itself. Initially, we hypothesized in DCIS increased necrosis would correlate with ductal size and in turn the distance from the center of the gland to vascular resources. This was not the case in our results. Also of interest, in a single case vasculature was observed inside the DCIS. This case was not found to contain necrosis and was ER + (Figure 4E).

Poor vascularization and necrosis was originally hypothesized to be a proxy for hypoxia induced cell death and thus an indicator of low estrogen availability. However, there are a number of plausible explanations (many of which may be responsible in part) why necrotic regions may play a role. In our previous work, we hypothesized that tumor heterogeneity could be predictable similar to that of a riparian zone in a desert environment. Oxygenated phenotypes or relatively highly perfused regions could be equivalent to mesic species and poorly vascularized (distal from a blood supply) would be equivalent to xeric species [15]. In this regard, ERpositive phenotypes are mesic while ER-negatives are xeric phenotypes.

Xeric habitats are formed by evaporation of water and accumulation of salt which results in salty soil that select for xeric species. In our scenario, hypoxic phenotypes may be shaped by a depletion of nutrients, oxygen and metabolites. That is why ER-negative cells may be adapted to tissue of poor vascularization and higher necrosis. Of course toxification (i.e. salty soil) in such an environment may be another plausible consideration. Regardless, this unavailability of estrogen is one reasonable explanation for estrogen-independent tissue selection. This may be a testable hypothesis in vitro or using techniques including laser capture microdissection to isolate specific regions of high vascularity within patient tumors and evaluating the estrogen concentrations. This is a key future direction for this research.

A significant limitation of our analysis is our inability to measure temporal variations in blood flow. That is, the cyclical and random variations in blood flow which have been extensively observed. These variations will result in temporal variations in estrogen concentration which could alter ER expression. This imprecise link of vascular density and blood flow could result in similar variations in the correlation between vascular density and ER expression.

\section{Conclusion}

In conclusion, we find ER expression and metrics of vascular density and blood flow in 24 clinical breast cancers show direct correlations between ER + tumors and blood vessel size and inverse correlation with necrosis consistent with predictions. This correlation, if confirmed, suggest strategies to promote intratumoral blood flow could be explored as a somewhat counter-intuitive approach to increase the efficacy of anti-estrogen drugs.

Due to natural selection, ER- tumors could be evolving in a way that resists (adapts to) the absence of estrogen. As a future direction, we hypothesize that anti-estrogen therapy (e.g. Tamoxifen) can select for ER-independent cells. In contrast, cyclic introduction of estrogen may improve survival rate by continually altering, rather than unilaterally shifting, toward an ER- population. In other words, this theory suggests that modulation (and not eradication or extinction of certain population) may prove to be an advantageous treatment strategy.

Furthermore, it may be possible that ER + cells cluster around vasculature and effectively act as a barrier. While this is a future direction of this research and has not yet been tested, it may explain how both populations coexist spatially in a single tumor. More interestingly, it may also be possible that this spatial pattern keeps ER- cells farther from blood vessels where they might enter the bloodstream and form metastatic tumors. ER- may be more prone to metastasize if ER + cells are less successful invading novel tissues. Future work should determine the spatial relationships around vasculature and the propensity for each population to metastasize. This more in depth assessment of regional distributions of ER + and 
ER- cells will be important to understand whether heterogeneous ER staining correlates directly with vessel distribution (i.e. whether ER + cells congregate nearer to the vessels within a tumor).

In summary, we conclude that ER status is selected for given vascular availability which could have meaningful and exploitable therapeutic decision making implications.

\section{Consent}

Written informed consent was obtained via Institutional Review Board from the University of South Florida approval for the use of patient information for the publication of this report and any accompanying images.

\section{Abbreviations \\ ER: Estrogen receptor; ER-: Estrogen receptor negative; ER+: Estrogen receptor positive; DAB: 3,3' diaminobenzidine (stain); DCIS: Ductal carcinoma in situ; H\&E: Hematoxylin and eosin; IDC: Intraductal carcinoma; IHC: Immunohistochemistry; $\mu \mathrm{m}$ : Micron; WSI: Whole slide images; NA: Numerical aperture; RGB: Red, green, blue; MMB: Marilyn M. Bui (author and pathologist).}

\section{Competing interests}

The authors declare that they have no competing interests.

\section{Authors' contribution}

$\mathrm{MCL}$ and $\mathrm{KOA}$ conceived of the study, designed the experiments and drafted the manuscript. MCL carried out the image acquisition and analysis studies. MMB selected the patient's for study participation and participated in many aspects of the pathological analysis. MCL, DV, RJG and MEI participated intellectually in the design and framing of the manuscript. MCL, JSB and RAG provided substantial intellectual direction and participated in experimental design, data analysis and drafting of the manuscript. All authors read and approved the final manuscript.

\section{Acknowledgements}

We thank Dr. Charles E. Bailey for his thorough discussion on current topic. This work has been supported by the Tissue Core and Analytic Microscopy Core and by funding from NIH/NCl U54CA143970.

\section{Author details}

${ }^{1}$ H. Lee Moffitt Cancer Center, 12902 Magnolia Drive, Tampa, FL 33612, USA ${ }^{2}$ Unit of Diseases and Diversity, Dept. of Molecular Biology, Institute of Endemic Diseases, University of Khartoum, Medical Campus, P. O. BOX 102, Khartoum, Sudan. ${ }^{3}$ University of Illinois at Chicago, Chicago, IL, USA.

\section{Received: 27 November 2013 Accepted: 25 March 2014}

Published: 23 April 2014

\section{References}

1. Thomas C, Gustafsson JÅ: The different roles of ER subtypes in cancer biology and therapy. Nat Rev Cancer 2011, 11(8):597-608.

2. Fishman J, Osborne MP, Telang NT: The role of estrogen in mammary carcinogenesis. Ann N Y Acad Sci 1995, 768:91-100.

3. Liehr JG: Is estradiol a genotoxic mutagenic carcinogen? Endocr Rev 2000, 21(1):40-54.

4. Devanesan P, Santen RJ, Bocchinfuso WP, Korach KS, Rogan EG, Cavalieri E: Catechol estrogen metabolites and conjugates in mammary tumors and hyperplastic tissue from estrogen receptor-alpha knock-out (ERKO)/Wnt-1 mice: implications for initiation of mammary tumors. Carcinogenesis 2001, 22(9):1573-1576.

5. Russo J, Russo $\mathrm{IH}$ : The role of estrogen in the initiation of breast cancer. J Steroid Biochem Mol Biol 2006, 102(1-5):89-96.

6. Yager JD, Davidson NE: Estrogen carcinogenesis in breast cancer. NEJM 2006, 354(3):270-282.
7. Hammond ME, Hayes DF, Dowsett M, Allred DC, Hagerty KL, Badve S, Fitzgibbons PL, Francis G, Goldstein NS, Hayes M, Hicks DG, Lester S, Love R, Mangu PB, McShane L, Miller K, Osborne CK, Paik S, Perlmutter J, Rhodes A, Sasano H, Schwartz JN, Sweep FC, Taube S, Torlakovic EE, Valenstein P, Viale G, Visscher D, Wheeler T, Williams RB, et al: American Society of Clinical Oncology; College of American Pathologists. (2010). American Society of Clinical Oncology/College of American Pathologists guideline recommendations for immunohistochemical testing of estrogen and progesterone receptors in breast cancer (unabridged version). Arch Pathol Lab Med 2010, 134(7):e48-e72.

8. Viale G, Regan MM, Maiorano E, Mastropasqua MG, Dell'Orto P, Rasmussen BB, Raffoul J, Neven P, Orosz Z, Braye S, Ohlschlegel C, Thürlimann B, Gelber RD, Castiglione-Gertsch M, Price KN, Goldhirsch A, Gusterson BA, Coates AS: Prognostic and predictive value of centrally reviewed expression of estrogen and progesterone receptors in a randomized trial comparing letrozole and tamoxifen adjuvant therapy for postmenopausal early breast cancer: BIG 1-98. J Clin Oncol 2007, 25(25):3846-3852.

9. Endo Y, Toyama T, Takahashi S, Sugiura H, Yoshimoto N, Iwasa M, Kobayashi S, Fujii Y, Yamashita H: High estrogen receptor expression and low Ki67 expression are associated with improved time to progression during first-line endocrine therapy with aromatase inhibitors in breast cancer. Int J Clin Oncol 2011, 16(5):512-518.

10. Khalique L, Ayhan A, Weale ME, Jacobs IJ, Ramus SJ, Gayther SA: Genetic intra-tumour heterogeneity in epithelial ovarian cancer and its implications for molecular diagnosis of tumours. J Pathol 2007, 211(3):286-295.

11. Li JQ, Xu BJ, Shakhtour B, Deane N, Merchant N, Heslin MJ, Washington K, Coffey RJ, Beauchamp RD, Shyr Y, Billheimer D: Variability of in situ proteomic profiling and implications for study design in colorectal tumors. Int J Oncol 2007, 31(1):103-111.

12. Iwasa $Y$, Michor F: Evolutionary dynamics of intratumor heterogeneity. PLoS One 2011, 6(3):e17866.

13. Gerlinger M, Rowan AJ, Horswell S, Larkin J, Endesfelder D, Gronroos E, Martinez P, Matthews N, Stewart A, Tarpey P, Varela I, Phillimore B, Begum S, McDonald NQ, Butler A, Jones D, Raine K, Latimer C, Santos CR, Nohadani M, Eklund AC, Spencer-Dene B, Clark G, Pickering L, Stamp G, Gore M, Szallasi Z, Downward J, Futreal PA, Swanton C: Intratumor heterogeneity and branched evolution revealed by multiregion sequencing. N Engl J Med 2012, 366(10):883-892.

14. Swanton C: Intratumor heterogeneity: evolution through space and time. Cancer Res 2012, 72(19):4875-4882.

15. Alfarouk KO, Ibrahim ME, Gatenby RA, Brown JS: Riparian ecosystems in human cancers. Evol Appl 2013, 6(1):46-53.

16. Pinzone JJ, Stevenson H, Strobl JS, Berg PE: Molecular and cellular determinants of estrogen receptor a expression. Mol Cell Biol 2004, 24(11):4605-4612.

17. Stoner M, Saville B, Wormke M, Dean D, Burghardt R, Safe S: Hypoxia induces proteasome-dependent degradation of estrogen receptor $a$ in ZR-75 breast cancer cells. Mol Endocrinol 2002, 16(10):2231-2242.

18. Shipitsin M, Campbell LL, Argani P, Weremowicz S, Bloushtain-Qimron N Yao J, Nikolskaya T, Serebryiskaya T, Beroukhim R, Hu M, Halushka MK, Sukumar S, Parker LM, Anderson KS, Harris LN, Garber JE, Richardson AL, Schnitt SJ, Nikolsky Y, Gelman RS, Polyakemail K: "Molecular definition of breast tumor heterogeneity". Cancer Cell 2007, 11(3):259-273.

19. Jiang Y, Pjesivac J, Freyer J: A Cellular Model for Avascular Tumor Growth. In Abstracts of ICSB 2002, the 3rd International Conference on System Biology - "The Logic of Life". Stockholm, Sweden: Karolinska Institutet; 2002:123-124. http://www.ki.se/icsb2002/abstracts.html.

20. Qureshi A, Pervez S: Allred scoring for ER reporting and it's impact in clearly distinguishing ER negative from ER positive breast cancers. J Pak Med Assoc 2010, 60(5):350-353.

21. Harvey JM, Clark GM, Osborne CK, Allred DC: Estrogen receptor status by immunohistochemistry is superior to the ligand-binding assay for predicting response to adjuvant endocrine therapy in breast cancer. J Clin Oncol 1999, 17(5):1474-1474.

22. Elston CW, Ellis IO: Pathological prognostic factors in breast cancer. The value of histological grade in breast cancer: experience from a large study with long-term follow up. Histopathology 1991, 19(5):403-410.

23. Kunz P, Hoffend J, Altmann A, Dimitrakopoulou-Strauss A, Koczan D, Eisenhut M, Bonaterra GA, Dengler TJ, Mier W, Haberkorn U, Kinscherf R: Angiopoietin-2 overexpression in morris hepatoma results in increased 
tumor perfusion and induction of critical angiogenesis-promoting genes. J Nucl Med 2006, 47(9):1515-1524.

24. Sorensen AG, Emblem KE, Polaskova P, Jennings D, Kim H, Ancukiewicz M, Wang M, Wen PY, Ivy P, Batchelor TT, Jain RK: Increased survival of glioblastoma patients who respond to antiangiogenic therapy with elevated blood perfusion. Cancer Res 2012, 72(2):402-407.

25. Overgaard J, Horsman MR: Modification of hypoxia-induced radioresistance in tumors by the use of oxygen and sensitizers. Semin Radiat Oncol 1996, 6:10-21.

26. Bernards R: Cancer: cues for migration. Nature 2003, 425(6955):247-248,

27. Clavo B, Robaina F, Catalá L, Pérez JL, Lloret M, Caramés MA, Morera J, López L, Suárez G, Macías D, Rivero J, Hernández MA: Effect of cervical spinal cord stimulation on regional blood flow and oxygenation in advanced head and neck tumours. Ann Oncol 2004, 15(5):802-807.

28. Jain RK: Normalization of tumor vasculature: an emerging concept in antiangiogenic therapy. Science 2005, 307(5706):58-62.

29. Teschendorff AE, Miremadi A, Pinder SE, Ellis IO, Caldas C: An immune response gene expression module identifies a good prognosis subtype in estrogen receptor negative breast cancer. Genome Biol 2007, 8(8):R157.

30. Fitzgibbons PL, Page DL, Weaver D, Thor AD, Allred DC, Clark GM, Ruby SG, O'Malley F, Simpson JF, Connolly JL, Hayes DF, Edge SB, Lichter A,

Schnitt SJ: Prognostic factors in breast cancer. College of American Pathologists Consensus Statement 1999. Arch Pathol Lab Med 2000, 124(7):966-978.

31. Vaupel P: Hypoxia in neoplastic tissue. Microvasc Res 1977, 13(3):399-408.

32. Bosari S, Lee AK, DeLellis RA, Wiley BD, Heatley GJ, Silverman ML: Microvessel quantitation and prognosis in invasive breast carcinoma. Hum Pathol 1992, 23(7):755-761.

33. Leek RD, Landers RJ, Harris AL, Lewis CE: Necrosis correlates with high vascular density and focal macrophage infiltration in invasive carcinoma of the breast. Br J Cancer 1999, 79(5/6):991.

doi:10.1186/1471-2407-14-279

Cite this article as: Lloyd et al:: Vascular measurements correlate with estrogen receptor status. BMC Cancer 2014 14:279.

\section{Submit your next manuscript to BioMed Central and take full advantage of:}

- Convenient online submission

- Thorough peer review

- No space constraints or color figure charges

- Immediate publication on acceptance

- Inclusion in PubMed, CAS, Scopus and Google Scholar

- Research which is freely available for redistribution

Submit your manuscript at www.biomedcentral.com/submit
() Biomed Central 